\title{
A Comparative Study of Ozone Generation Using Pulsed and Continuous AC Dielectric Barrier Discharges
}

\author{
G. M. Huang, T. Wang, I.V. Timoshkin, S. J. MacGregor, M. J. Given, M. P. Wilson \\ Department of Electronic and Electrical Engineering, University of Strathclyde, Royal College Building, \\ 204 George street, Glasgow, UK, G1 1XW
}

\begin{abstract}
This paper presents a comparative study of ozone generation under pulsed and continuous ac dielectric barrier discharge (DBD). An oxygen-fed DBD reactor with a narrow discharge gap of $0.4 \mathrm{~mm}$ was used in the experiments. DBD discharge modes under pulsed and continuous ac energisation were investigated and compared in this work. Negative impulses with the pulse length of $500 \mathrm{~ns}$ and repetition rate of 200 pps were employed to produce ozone at four different concentrations of $18.4 \mathrm{~g} / \mathrm{Nm}^{3}, 34.8 \mathrm{~g} / \mathrm{Nm}^{3}, 38.1 \mathrm{~g} / \mathrm{Nm}^{3}$ and $52.5 \mathrm{~g} / \mathrm{Nm}^{3}$, while in the case of ac energisation, sinusoidal voltage with the frequency of $25 \mathrm{kHz}$ was applied to produce ozone at similar concentrations. The discharge power and ozone production efficiency at these ozone concentrations were obtained and compared for both energisation modes. It is shown that both pulsed and continuous ac dielectric barrier discharges have a filamentary mode and continuous ac energisation results in $18 \%$ increase in the efficiency as compared with pulsed energisation.
\end{abstract}

\section{I.INTRODUCTION}

Ozone is a strong oxidant and disinfectant. It is widely used for industrial applications including waste water and drinking water treatment, exhaust gas treatment and pulp bleaching. Dielectric barrier discharge, characterized by the presence of at least one insulating layer between two planar or cylindrical electrodes, provides an effective method for ozone production [1]. Commercial ozone generator based on DBDs is usually driven by an ac power supply from a few hundred hertz to kilo hertz. However, the ozone production efficiency under ac operation is relatively low. In commercial systems, at the concentration of $147.8 \mathrm{~g} / \mathrm{Nm}^{3}$ (10\% by weight), the efficiency is less than $150 \mathrm{~g} / \mathrm{kWh}$. Compared with continuous ac operation, pulsed power supply provides higher breakdown electric field. This results in generation of high-energy electrons that produces the oxygen atom which is necessary for ozone formation. Also, short pulse operation does not produce much heat which is detrimental to ozone production. Many studies on the pulsed ozone production were carried out aiming to improve ozone production efficiency [2-5]. In these studies, ozone was produced using pulsed streamer discharges in a coaxial wire cylinder $[2,3]$ or spiral cylinder with or without a dielectric $[4,5]$. Ozone production efficiency reported by these researches is quite promising. Chalmers reported efficiency value $300 \mathrm{~g} / \mathrm{kWh}$ using short pulse at $20 \mathrm{~ns}$ [2]. W.J.M. Samaranayake reported efficiency value $202 \mathrm{~g} / \mathrm{kWh}$ at the low pulse rate of $25 \mathrm{pps}$ [4]. However, these experiments were conducted at low ozone concentration (below $10 \mathrm{~g} / \mathrm{Nm}^{3}$ ). From the results achieved in these studies, it can be seen that the efficiency drops quickly when the ozone concentration is above $10 \mathrm{~g} / \mathrm{Nm}^{3}$.

In the present work, ozone production efficiency for concentrations up to $50 \mathrm{~g} / \mathrm{Nm}^{3}$ under pulsed and continuous ac dielectric barrier discharges has been investigated. DBD discharges mode and ozone production efficiency under both energisations were compared. Results achieved in this work were also compared with the literature data.

\section{II.EXPERIMENTAL PROCEDURE}

\section{A. Ozone reactor and gas handling system}

Fig. 1 shows the cross-section of the ozone reactor used in the present study. This reactor has a cylindrical electrode topology. The outer $270 \mathrm{~mm}$ long stainless steel tube serves as a grounding electrode, the temperature of which was kept at $15^{\circ} \mathrm{C}$ by circulating water. The inner electrode is a stainless steel rod surrounded by water with conductivity of $60 \mu \mathrm{s} / \mathrm{cm}$ inside a borosilicate glass tube with the wall thickness of $1.2 \mathrm{~mm}$ (thickness of water layer is $0.3 \mathrm{~mm}$ ). . A quartz window was placed parallel to the cross section of discharges space, through which the emitted light from discharges can be detected.

In the present work, oxygen with the purity of $99.5 \%$ and dew point of $-40^{\circ} \mathrm{C}$ was fed into the reactor. The gas flow rate in the experiment was kept at $0.2 \ell / \mathrm{min}$ and the gas pressure was atmospheric pressure. Ozone concentration was monitored by IN-USA Mini-HiCon Ozone Analyzer based on $254 \mathrm{~nm}$ UV radiation absorption. The schematic diagram of gas handling system for ozone generation can be found in the previous work [6]. 


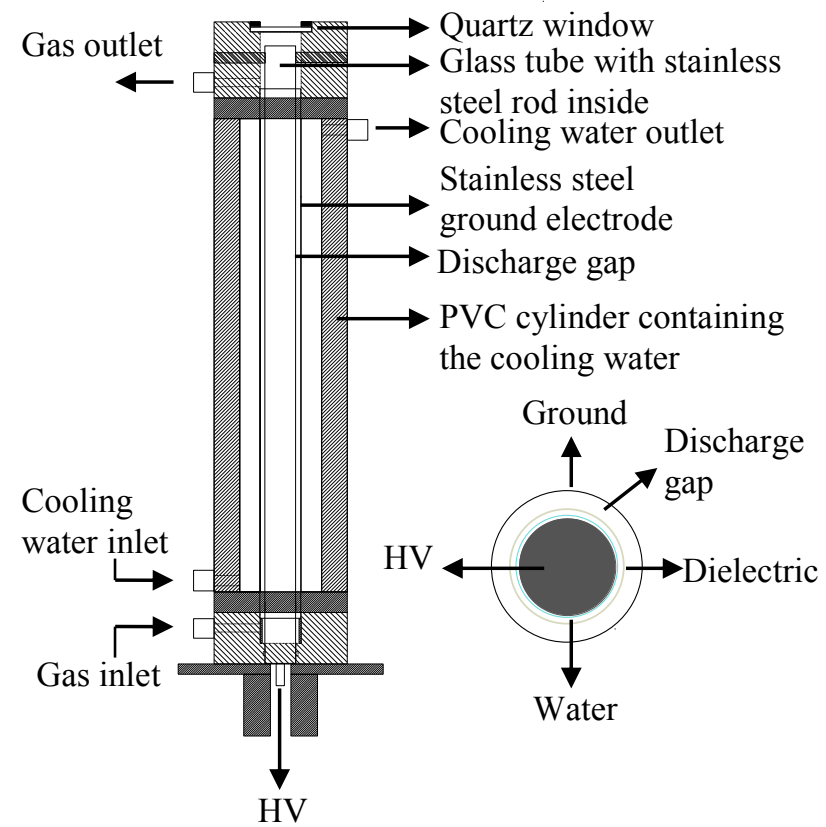

Figure 1. Schematic diagram of ozone reactor and its cross-sectional view

\section{B. Power supply and electrical measurement system}

Electrical circuit of power supplies employed in this work is shown in Fig. 2. In the pulsed power supply, the pulsed voltage was generated by charging a capacitor of $1 \mathrm{nF}$ fed by a $20 \mathrm{kV}-10 \mathrm{~mA}$ high voltage DC power supply and $1 \mathrm{M} \Omega$ charging resistor. Resistor of $220 \Omega$ was connected in parallel with ozone reactor for charging and discharging the capacitive load and it determines the pulse length of pulse voltage across the reactor. The pulse length is defined as the full-width half maximum (FWHM) of the pulsed voltage. In this work, negative pulsed voltage with FWHM of 500 ns was achieved. A trigger switch triggered by a trigger generator was used in the experiment to provide a repetition rate of $200 \mathrm{pps}$ for ozone production. In the $25 \mathrm{kHz}$ ac power supply, a thyristor controlled frequency inverter was stepped up by a high frequency transformer and connected to the ozone reactor with a series-compensated resonant inductor of 60 $\mathrm{mH}$. The average power output of this inverter can be linearly regulated with pulse density modulation (PDM) strategy. The PDM was set to be $5 \%$ in this work.

The voltage across the reactor was measured by Tektronix P6015A high voltage probe (bandwidth 75 $\mathrm{MHz}$, division ratio 1000:1). The discharge current was measured by Pearson current probe (Model 6585) with the bandwidth from $400 \mathrm{~Hz}$ to $250 \mathrm{MHz}$ and rise time of 1.5 ns. A Hamamatsu photomultiplier (Model H10721-01) with rise time of $0.57 \mathrm{~ns}$ was employed to detect emitted light from discharges. The voltage, current and emitted light signal were recorded by a Lecroy oscilloscope (Waverunner $104 \mathrm{Xi}, 1 \mathrm{GHz}, 5 \mathrm{GS} / \mathrm{s}$ ).
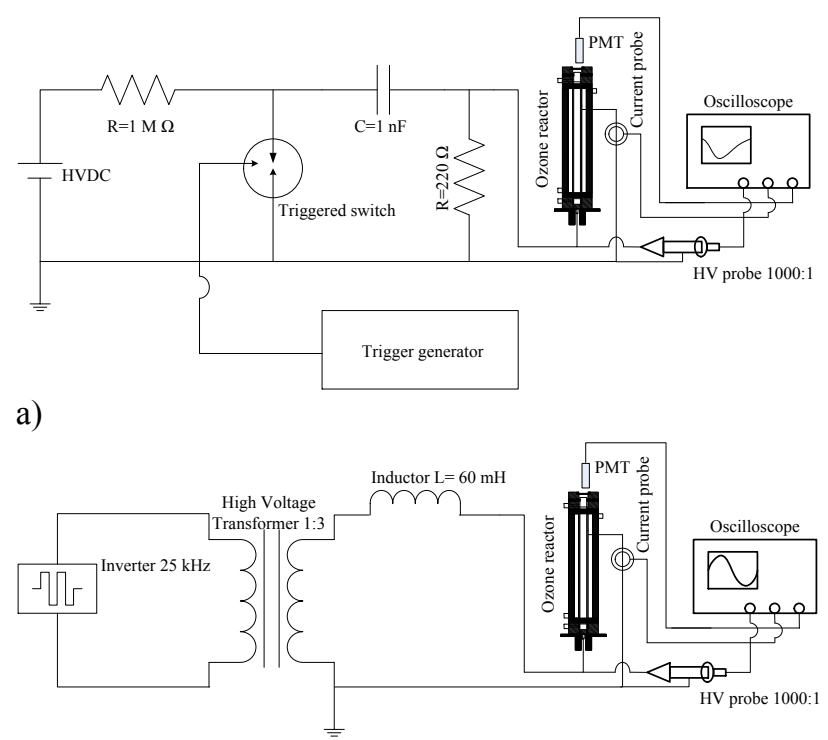

b)

Figure 2. Schematic diagram of electrical circuits of a) pulsed power supply and $25 \mathrm{kHz}$ ac power supply

Discharge power was determined by the integration of the instantaneous product of the digitized voltage and current signals from the scope. The specific power in this work is defined as the ratio of discharge power and gas flow rate with the unit of $\mathrm{J} / \ell$.

Ozone production efficiency, $\eta(\mathrm{g} / \mathrm{kWh})$, can be calculated by the Eq. (1) as follow:

$$
\eta=\frac{F \times 60 \times N}{P}
$$

In Eq. (1), $\mathrm{F}$ is the flow rate of oxygen and ozone mixture gas $(\ell / \mathrm{min}), \mathrm{N}$ is the ozone concentration measured by ozone analyzer $(\mathrm{mg} / \ell)$ and $\mathrm{P}$ is the average discharge power (W).

\section{III.RESULTS AND DISCUSSIONS}

\section{A. DBD discharges modes}

DBD discharges mode under pulsed power and sine wave ac power supply were studied by measurement of voltage across the reactor, discharge current and emitted light signal from the discharges under both energisations. Fig. 3 and Fig. 4 show the voltage, current waveform and emitted light signals from discharges under pulsed power and sine wave ac power supply respectively. In pulsed operation, the peak voltage applied was $18 \mathrm{kV}$. The current waveform has a peak value of $75 \mathrm{~A}$. Compared with the current waveforms in sine wave operation which has impulsive current superimposed into the displacement 
current, the current measured in the pulsed operation doesn't show the impulsive component. This is probably due to the fact that the magnitude of impulsive component is much smaller compared with the displacement current component, so it cannot be distinguished. From the emitted light signals, it can be seen that the first streamer discharge in pulsed energisation occurs when the voltage rises to $11 \mathrm{kV}$. After this breakdown onset voltage, there are many emitted light pulses detected but with a smaller magnitude. These emitted lights represent the filamentary discharges under pulsed energisation [7]. It is interesting to note that there are still emitted lights detected even after the peak voltage in pulsed energisation. This is different from the sine wave energisation in which case the discharges stop when the voltage reaches the peak value. Also, in sine wave energisation, the discharges start from a low voltage value. From Fig. 4, positive discharges start from $-1.2 \mathrm{kV}$ and negative discharges start from 1.4 $\mathrm{kV}$. This is due to a local electric field enhancement by the surface charges accumulated on the dielectric from the last discharges performance. From Fig. 4, it can be observed that impulsive currents are significantly lower during the negative voltage half-cycle as compared with that during the positive voltage half-cycle. Reason for that is still not clear at the present work.

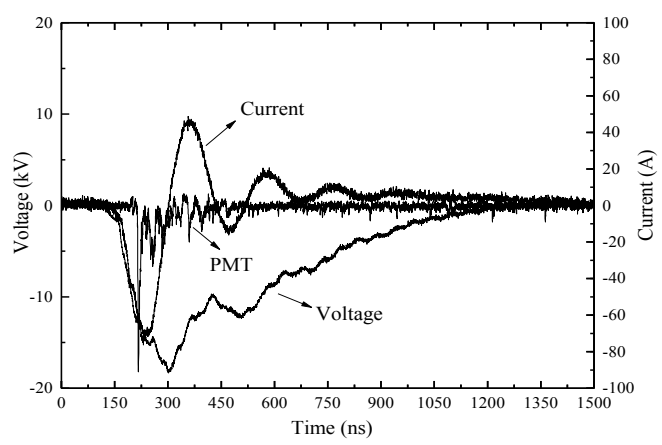

Figure 3. Voltage, current and emitted light signal from discharges energised by pulsed power supply

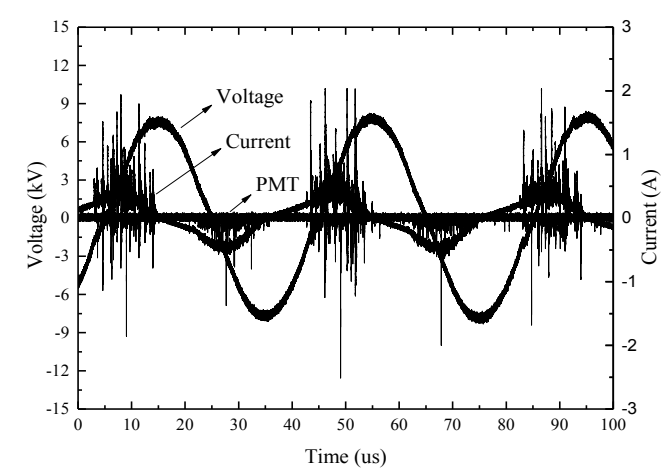

Figure 4. Voltage, current and emitted light signal from discharges energised by sine wave ac power supply

\section{B. Ozone generation performance}

Ozone formation can be divided into two steps. First step is the dissociation of oxygen molecules by electrons impact that occur in the following two reactions:

$$
\begin{aligned}
& e+O_{2} \rightarrow e+O_{2}\left(A^{3} \Sigma_{u}^{+}\right) \rightarrow e+O\left({ }^{3} P\right)+O\left({ }^{3} P\right) \\
& e+O_{2} \rightarrow e+O_{2}\left(B^{3} \Sigma_{u}^{-}\right) \rightarrow e+O\left({ }^{3} P\right)+O\left({ }^{3} D\right)
\end{aligned}
$$

Ozone is subsequently formed after the dissociation of oxygen molecule by the following three body reaction:

$$
\mathrm{O}+\mathrm{O}_{2}+\mathrm{M} \rightarrow \mathrm{O}_{3}+\mathrm{M}
$$

In this reaction, $M$ is a third collision partner that can be oxygen atom $\mathrm{O}, \mathrm{O}_{2}$ or $\mathrm{O}_{3}$. Fig. 5 and Fig. 6 shows the ozone concentration and discharge power under pulsed and ac energisation. It can be seen that ozone concentration and discharge power increases almost linearly with the applied voltage. Four ozone concentrations of $18.4 \mathrm{~g} / \mathrm{Nm}^{3}, 34.8 \mathrm{~g} / \mathrm{Nm}^{3}, 38.1 \mathrm{~g} / \mathrm{Nm}^{3}$ and $52.5 \mathrm{~g} / \mathrm{Nm}^{3}$ were achieved under pulsed energisation and four similar ozone concentrations of $21.4 \mathrm{~g} / \mathrm{Nm}^{3}$, $33.8 \mathrm{~g} / \mathrm{Nm}^{3}, 43.4 \mathrm{~g} / \mathrm{Nm}^{3}$ and $51.4 \mathrm{~g} / \mathrm{Nm}^{3}$ were achieved under $25 \mathrm{kHz}$ sine wave energisation. Fig. 7 shows curves of ozone concentration versus specific power under both energisations. It can be seen that ozone performance in both cases demonstrate similar trend. At same specific power, the ac energisation provides higher ozone concentration than pulsed energisation. From Fig. 7, at the specific power of $959 \mathrm{~J} / \ell$ under pulsed energisation, ozone concentration is $38.1 \mathrm{~g} / \mathrm{Nm}^{3}$ while at the specific power of $933.45 \mathrm{~J} / \ell$ under ac energisation, the ozone concentration is $43.4 \mathrm{~g} / \mathrm{Nm}^{3}$. In the literature, T. Namihira et al. achieved $30 \mathrm{~g} / \mathrm{Nm}^{3}$ at the specific power of $1000 \mathrm{~J} / \ell$ using pulsed corona discharge in a spiral cylinder electrode configuration [5]. Y. Nakai et al. reported 20 $\mathrm{g} / \mathrm{Nm}$ at specific input energy of $600 \mathrm{~J} / \ell$ under ac high voltage in a parallel plane type DBD ozonizer [8]. Fig. 8 shows ozone production efficiency as a function of ozone concentration. It demonstrates that ozone generation efficiency is relatively consistent in the investigated range with a small drop towards higher concentration. It shows that $25 \mathrm{kHz}$ ac energisation results in more efficient ozone production as compared with impulsive energisation. At the concentration of $33.8 \mathrm{~g} / \mathrm{Nm}^{3}$, the ozone yield is 163 $\mathrm{g} / \mathrm{Nm}^{3}$ under continuous ac and $133.3 \mathrm{~g} / \mathrm{Nm}^{3}$ at 34.8 $\mathrm{g} / \mathrm{Nm}^{3}$ under pulsed power, $18 \%$ lower. In the literature, T. Namihira et al. attained an ozone production efficiency $100 \mathrm{~g} / \mathrm{kWh}$ at $30 \mathrm{~g} / \mathrm{Nm}^{3}$ [5]. Results from Y. Nakai et al. demonstrate that ozone yield was $125 \mathrm{~g} / \mathrm{Nm}^{3}$ at about 20 $\mathrm{g} / \mathrm{Nm}^{3}$ [8]. The ozone yield achieved in this present work is better than the above literature results. 


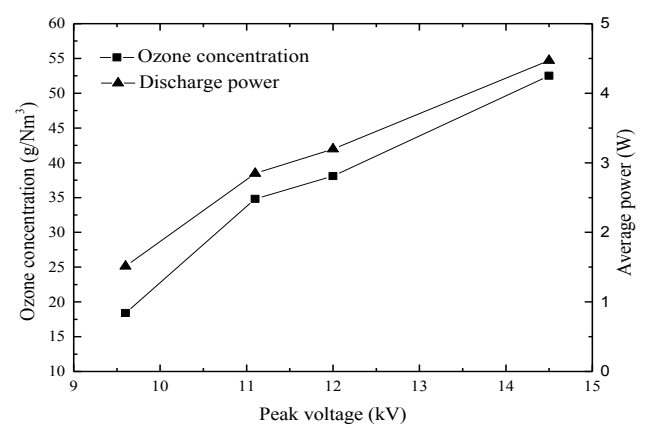

Figure 5. Ozone concentration and discharge power at different peak voltage under pulsed energisation

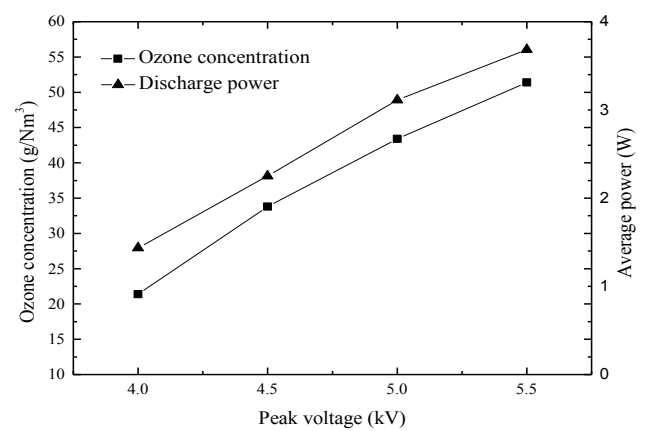

Figure 6. Ozone concentration and discharge power at different peak voltage under ac energisation

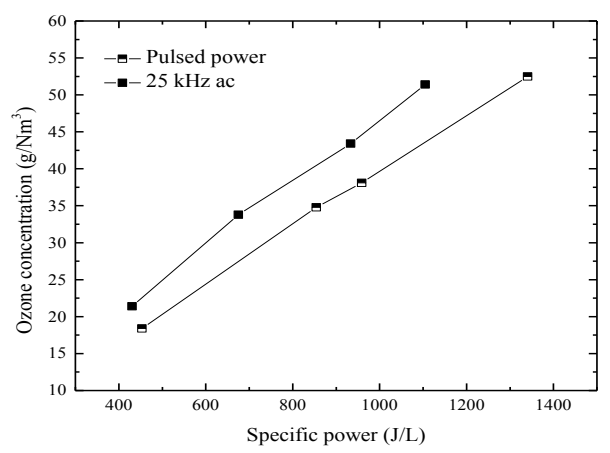

Figure 7. Ozone concentration as a function of specific power under pulsed and ac energisation

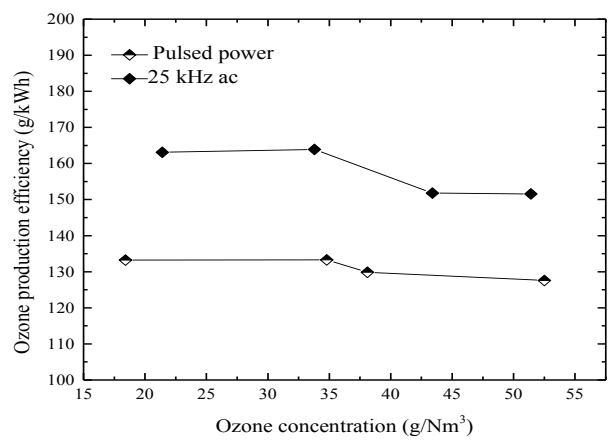

Figure 8. Ozone production efficiency as a function of ozone concentration under pulsed and ac energisation

\section{IV.CONCLUSIONS}

1. DBD discharge modes under pulsed and continues ac energisation were investigated and compared.

2. Filamentary discharges mode has been observed for both pulsed and $25 \mathrm{kHz}$ ac energisation regimes in oxygen.

3. Ozone concentration increases with applied voltage for both energisation regimes.

4. Continuous ac energisation results in $18 \%$ more efficient ozone production as compared with pulsed energisation.

\section{V.REFERENCES}

[1] U. Kogelschatz, B. Eliasson, and W. Egli, "Dielectricbarrier discharges. Principle and applications," Journal de Physique IV (Colloque), vol. 7, pp. 47-66, 1997.

[2] I. D. Chalmers, L. Zanella, and S. J. MacGregor, "Ozone synthesis in oxygen in a dielectric barrier free configuration," in Pulsed Power Conference, 1995. Digest of Technical Papers., Tenth IEEE International, 1995, pp. 1249-1254 vol.2.

[3] I. D. Chalmers, L. Zanella, S. J. MacGregor, and I. A. Wray, "Ozone generation by pulsed corona discharge in a wire cylinder arrangement," in Electro-Technologies for Waste Processing and Purification, IEE Colloquium on, 1994, pp. 6/1-6/4.

[4] W.J.M. Samaranayake, Y. Miyahara, T. Namihira, S. Katsuki, R. Hackam and H. Akiyama, "Ozone Production Using Pulsed Dielectric Barrier Discharge in Oxygen," IEEE Transactions on Dielectrics and Electrical Insulation, vol. 7, pp. 849-854, 2000.

[5] T. Namihira, S. Katsuki, H. Akiyama, and R. Hackam, "Characteristics of ozonizer using pulsed power," in IEEE Pulsed Power \& Plasma Science Conference 2001, p. 306.

[6] G.M. Huang, T. Wang, I.V. Timoshkin, S.J.

MacGregor, M.J. Given, and M. P. Wilson, "Investigation of ozone generation using dielectric barrier discharges at $50 \mathrm{~Hz}, 2.6 \mathrm{kHz}$ and $20 \mathrm{kHz}$," presented at the Proceedings. 19th International Conference on Gas Discharges and Their Applications, Beijing, 2012.

[7] L. Shuhai and N. Manfred, "Excitation of dielectric barrier discharges by unipolar submicrosecond square pulses," Journal of Physics D: Applied Physics, vol. 34, pp. 1632-1638, 2001.

[8] Y. T. Nakai, Ami; Osawa, Naoki; Yoshioka, Yoshio; Hanaoka, Ryoichi, "Comparison of Ozone Generation Characteristics by Filamentary Discharge Mode and Townsend Discharge Mode of Dielectric Barrier Discharge in Oxygen," Journal of Chemistry \& Chemical Engineering, vol. 5, pp. 1107-1110, 2011. 